\title{
The Effect of Using Anticipation Guide Strategy on Iranian EFL Learners' Comprehension of Culturally Unfamiliar Texts
}

\author{
Mona Roozkhoon (Corresponding author) \\ English Department, Faculty of Literature \& Humanities, \\ Islamic Azad University, Bandar Abbas Branch, Bandar Abbas , Iran \\ E-mail: roozkhoon.mona@hotmail.com \\ Elham Rahmani Samani \\ English Department, Faculty of Literature \& Humanities, \\ Islamic Azad University, Najaf Abad Branch, Najaf Abad, Iran \\ E-mail: rahmani.535@hotmail.com
}

\section{Doi:10.5901/mjss.2013.v4n6p127}

\begin{abstract}
This study investigated the effect of employing anticipation guide as a prereading strategy on EFL learners' comprehension. 40 intermediate female learners were participated in the present study. All participants were native speakers of Persian. They were divided into two groups: Group one $(n=20)$ as the experimental group and group two $(n=20)$ as the control one. The experimental group received treatments but control group did not receive any treatments. First, the participants were given a pretest to check their comprehension before the treatments. Then, all participants learned reading sections in their instructional book (summit 1A). Group 1 learned reading sections through application of anticipation guide strategy as a prereading strategy and group 2 learned reading sections in the traditional way. Finally, the researcher used the posttest in order to evaluate students' reading ability after using strategies. The posttest items were the same as the pretest. The results showed that using anticipation guide had positive effect on Iranian EFL learners' comprehension of culturally unfamiliar texts. This study encourages instructors to construct authentic environment in educational settings through employing beneficial strategies in an efficient manner in their instructional schedules.
\end{abstract}

Keywords: anticipation guide; prereading strategy; prior knowledge; culturally unfamiliar texts; EFL learners

\section{Introduction}

Readers can use different tactics as reading strategies to activate their background knowledge in order to comprehend the text better. Reading strategies are classified into three parts: prereading, during reading, and postreading strategies. Some researchers such as Anderson (1999), O'Brien (2007), and Ringler and weber 1984 (as cited in Yusuf, 2011) found that using strategies especially some prereading strategies can assist students in constructing a link between the knowledge that they acquired previously and the new knowledge they will gain in future; in this line, it seems that learning the strategies and various ways of using them are important in text processing.

According to Erten and Razi (2009), familiarity with cultural norms has a significant role in understanding and sometimes deficient reading is the result of lacking cultural familiarity. On the one hand, Iranian EFL learners like other ELL's can use some reading strategies. On the other hand, they prepare strategies to compensate their lack of cultural knowledge and develop their comprehension of a text which is culturally unfamiliar. The present study tried to answer the following research questions.

1. Is there any significant improvement in Iranian EFL learners' performances on reading comprehension quizzes while using anticipation guide?

2. Does anticipation guide have any effects on Iranian EFL learners' reading comprehension?

As Bell and Lee (2005) believed, learners could increase their prior knowledge and made interaction with the text to be read by using anticipation guide. This strategy helped instructors to assess learners' previous knowledge. Also, if learners need more prior knowledge, their instructor can demonstrate this before reading. Therefore, anticipation guide could stimulate learners' interest to know more about the subject matter. 
According to Lawson (2002, as cited in Kozen et al., 2006), anticipation guide is easy to accomplish and it is an effective teaching tool that instructors can use in educational settings. Anticipation guide is not as well known as other prereading strategies but it is so beneficial like other reading strategies. This is a prereading strategy which can activate learners' prior knowledge and get them interested in the topic which they are going to read. In using this prereading strategy which is known as anticipation guide, the researcher gives some general statements to students. Based on anticipation guide' process, the statements are relevant to the theme which the learners are going to read. In other words, the statements are based on the texts' concepts. Learners answer each statement and they should make clear whether they agree or disagree with the statements.

\section{Literature Review}

In many countries, many instructors teach foreign languages. Although they never communicate with native speakers, they have access to the handouts and publications or analytical and technical journals. Some of those instructors read publications and journals in order to do additional studies, whereas reading in another language is enjoyable for some others in their leisure time and they can be familiar with the wider world through it. High level of reading can help expert readers develop their apprehension and perception of written pages of different cultures, various thinking ways, newest findings and so forth, without further help from teachers. Moreover, it helps expert readers approach a book or magazine individually. Being expert in reading also helps readers promote their reading skill in one particular language even when they finished their study (Rivers, 1981). As Rivers (1981, p. 259) stated "reading is the most important activity in any language class, not only as a source of information and a pleasurable activity, but also as a means of consolidating and extending one's knowledge of the language."

\subsection{Reading approaches}

As stated by Boyle and Scanlon (2010), there are three types of reading approaches or reading models. Reading models provide a significant role in understanding the texts' contents. These models instruct the teachers to know how they can guide readers to read. The first model is bottom up model, in which students concentrate on printed words in order to get the meaning of the text. The second one is top down model. The proponents of top down model believed that reading is an active process. In this model, readers use their background knowledge to make sense of the texts. The third one is interactive model. Interactive model is combination of both top down and bottom up process. This model demonstrated that if the purpose of reading is recognition of individual words. Teacher should concentrate on phonological skills but if the purpose of reading is comprehension, the teacher should emphasizes on comprehension strategies.

\subsection{Reading components}

According to Jacobson (2007), reading consists of four core components: alphabetic, fluency, vocabulary, and comprehension. As stated by Kruidenier (2002, as cited in Jacobs, 2007), when the individuals engage in reading, they should be able to recognize each word (alphabetic) and make connection between each word and its meaning based on the stored knowledge in their mind (vocabulary). Also, the individuals also should be able to process each phrase and sentence fast in order to recall the information during reading. Moreover, based on the previous studies in this context, some investigators such as Sedita (2005) investigated effective vocabulary instruction and found that reading is composed of five essential components.

\subsubsection{Phonemic awareness}

Phonemic awareness is defined in numerous different ways. Schuele \& Boudreau (2008, as cited in Morton, 2011) suggested that words are constructed from smallest units of sounds and phonemic awareness was manipulation of individual sounds.

According to Kleeck, Gillam, and McFadden (1998, p. 67), "phonemic awareness is required for grasping the alphabetic principle, knowledge that words are composed of individual letters that in turn correspond to sounds within spoken words." 


\subsubsection{Phonics}

Ehri et al. (2001, p. 394) defined phonics as combination of "consonant letters and sounds and short and long vowel letters and sound and vowel and consonant diagraphs (e.g. oi, ai, sh, th)."

\subsubsection{Vocabulary}

Baumann et al. (2003) stated that vocabulary instruction is "how to derive word meanings through morphemic analysis and infer word meaning through contextual analysis" (p. 448).

\subsubsection{Fluency}

Armbruster et al. (2001) suggested that fluency is the ability to read a text accurately and quickly. The fluent readers can recognize words automatically when they read silently. Also, they can read aloud effortlessly. Readers who are not fluent, read slowly, word by word.

\subsubsection{Comprehension}

Snow (2002) stated that comprehension includes three important elements, such as "the reader who is doing the comprehending, the text that is to be comprehended, and the activity in which comprehension is a part" (p. 11).

Comprehension involves "ability to activate one's knowledge about a topic, self question, identify main ideas, and supporting details, paraphrase, and summarize" (Bryant et al., 1999, p. 296). Lots of researchers (Goldsman \& Bisanz, 2002; Jenkins, 1979; Van Den Broek, Fletcher, \& Risden, 1993; Van Den Broek \& Kremer, 1999 as cited in Kendeou \& Broek, 2007) suggested that numerous factors have strong impact on learners' comprehension like, readers' characteristics, texts' structure, and the educational contexts in which reading occurs.

\subsection{Reader's Role in Comprehension}

Snow (2002) suggested that readers bring a wide range of their abilities in reading process. These include cognitive capacities (e.g., attention, memory, critical analytic ability, inferencing, visualization ability), motivation (a purpose for reading, an interest in the content being read, self-efficacy as a reader), and various types of knowledge (vocabulary, domain and topic knowledge, linguistic and discourse knowledge, knowledge of specific comprehension strategies) and experiences.

\subsubsection{Cultural Schemata and Comprehension}

Omaggio (2001, as cited in Kreishan \& Saidat, 2011, p. 334) defined schema as "the previously acquired knowledge structures accessed in the comprehension process." Bartlett (1932) also defined schema as "an abstract textual structure that the comprehender makes use of to understand a given text." (p.14) Gunning (1996) also gave another definition for schema as "organized knowledge that one already has about people, places things, and events." (p. 64). In a different view, Nassaji (2002, as cited in Erten \& Razi, 2009, p. 444) defined schema theory as "preexisting knowledge structures stored in the mind." Erten and Razi (2009) investigated the effect of cultural familiarity on reading comprehension. There were forty four participants and they were divided into four groups. In this study, the investigators obtained two results. The first result revealed that "cultural familiarity facilitates comprehension" (p. 71), and the second one showed that reading strategies is a powerful way for activating students' schema knowledge and it helps students to be strategic readers.

\subsubsection{The Effect of Prior Knowledge on Comprehension}

Warsnak (2006) examined the effect of activating prior knowledge before reading on students with and without learning disabilities. Twenty one students participated in this study. The individuals were divided into two groups. One group consisted of students without learning disability and the second group were students with learning disabilities. The results showed that that $40 \%$ of participants with learning disabilities improved their reading comprehension by activating prior 
knowledge; similarly, $64 \%$ of the individuals without learning disabilities did too. In general, this study revealed that students with learning disabilities had little comprehension improvement. Students without learning disability also enhanced their fluency and comprehension by means of activation of prior knowledge.

Chen (2008) investigated the effect of background knowledge and previews on elementary native mandarinspeaking English language learners' reading comprehension. The results of the study showed a statistical interaction between the type of book (familiar vs. unfamiliar) and the preview intervention (preview vs. no preview). Findings revealed that the individuals obtained high score in comprehension when they received previewing before reading culturally unfamiliar texts. In short, the investigator found that using previews and culturally familiar texts could make comprehension easy.

\subsection{Texts' Role and Comprehension}

Texts' features have a great influence on comprehension. During reading process, readers can make different representations such as (surface code, text base and mental model) that are essential for comprehending.

\subsection{Transaction and Comprehension}

Some researchers like Bainbriedge and Pantaleo (1999) used the terms interaction and transaction interchangeably. They said "readers-response theories differ in emphasis they place on the text or the reader in regard to the creation of meaning, but all believe that readers actively construct meaning as they interact or transact with texts" (p. 153).

Rosenblatt (1973, as cited in Fox, 1996) stated that the act of reading involves 1) the text itself, 2) the situation and environment in which the reading occurs, and 3) the reader herself-her experience, background knowledge, mental schemata, attitudes, and values. These three elements interact, or transact with each other in order for readers to construct meaning.

Some researchers such as Pardo (2004) used the term transaction instead of the term interaction. He believed that in comprehension process, transaction happens between the reader, the text's feature and the context. In this regard, the researcher first tried to explain the differences between transaction and interaction and then defined transaction in comprehension process. Due to this purpose, the researcher referred to some previous investigation in this area. Cuffaro (1995) mentioned that interaction refers to the function of individual entities as the separate units but transaction refers to transformation not separation. In other words, it refers to both action between and action within. Based on this definition, the primary focus is on occurring situation. As a transactional perspective revealed, an "element" is a beneficial and important unit and its specific character clarified from the role that it plays in the transaction. Based on this perspective, the transaction is the goal. In other words, a combination of elements that have an independent existence cannot create a transaction. On the contrary, something that is considered as an element is dependent on its role within a transaction (Bernstein, 1966, as cited in Cuffaro, 1995). Some other researchers used both words with each other, for example, Flood et al. (2003) said "researchers have found that competent readers actively construct meaning through an integrative process in which they "interact" and "transact" with the words on the page" (p. 931).

\subsection{Using Reading Strategies and Comprehension}

Cogmen and Saracaloglu (2009) examined students' usage of reading strategies in the faculty of education. The findings revealed that using reading strategies can promote learners academic success and proficient readers use reading tactics during reading process. Findings also showed that by using reading strategies, college students can promote their comprehension. Thus, the learners should know about how to use reading tactics. The results of this study showed that college students should be informed about metacognition and metacognitive reading strategies. Also, this study showed that there is a positive relationship between using strategies and being successful in academic settings.

Zoghi et al. (2010) investigated EFL reading comprehension. The researchers found that deficient readers are incapable in critical reading. Findings also revealed that Iranian academic settings should concentrate on using strategic reading behaviors. The findings showed that Iranian EFL learners are limited to rote memorization and the reason is that the system of education in Iran is based on GTM. In text's processing, EFL learners just looking for the meaning of the words and they have difficulty in understanding the whole text because the learners are not familiar with the cultural norms. Sometimes, EFL learners use dictionary in order to interpret the meaning of words but they are incapable in interpretation of the meaning of the text. Findings also revealed that deficiency in reading is due to difficulty in "above the 
word level comprehension process." The researchers suggested that EFL learners should learn reading strategies because effective strategies help EFL learners and especially poor comprehenders construct the meaning of the text. Thus, by using reading strategies, L2 poor comprehenders can synthesize meaning and promote their comprehension. So, instructors should teach strategy instruction to learners.

\subsubsection{Prereading Strategies}

Ringler and weber (1984, as cited in Yusuf, 2011) believed that prereading activities are enabling activities because they supply readers' sufficient background knowledge for better understanding. Prereading activities can provide prior knowledge for readers in order to assist them in building background. In this regard, Yusuf (2011) conducted a study on this title "the effect of prereading activities on students' performance in reading comprehension in senior secondary schools." In this study, 50 (male and female) students from two senior secondary schools were selected. The participants were divided into two equal groups. Thus, twenty five students were in experimental group and twenty five in control one. The findings revealed that prereading activity had positive effect on learners' comprehension. According to Hansel (as cited in Taglieber et al., 1988, p. 456), not only do prereading activities prepare native speakers for the concepts that follow, but by making the reading task easier and connecting the new content more meaningfully to prior knowledge, prereading activities make reading a more enjoyable task.

\subsubsection{During Reading Strategies}

Grabe and Stoler (as cited in Murcia, 2001) defined during reading instruction and they stated that during reading instruction assists student consider troublesome concepts, it helps students try to get the aim of writing or the main concepts of the texts. In addition, it can help individuals examine the relation among different opinions and characters.

\subsubsection{Post-reading Strategies}

Grabe and Stoler (1994, as cited in Murcia, 2001) defined post reading instruction. They asserted that post reading instruction enhance students knowledge of the texts. Based on this instruction students should understand all important points and detailed information from the texts. In this instruction, students apply new information in other activities such as reading and writing.

\subsection{Prereading Strategies and Comprehension}

Bransford (1979, as cited in Dole et al., 1996) stated that "the presentation of information that helps people activate appropriate knowledge can have powerful effects on their abilities to comprehend, to remember, and to solve problems" (p.141).

Thongyon and Chiramanee (2011) investigated on this title the effects of prereading activities on reading comprehension ability. Sixty participants took part in this study. The researchers investigated both guessing story content by pictures and prereading questioning activities. The results showed that employing both prereading activities showed positive effect on students' comprehension but guessing story content by pictures was more effective than prereading questioning activities.

Alemi and Ebadi (2010) investigated the effect of prereading activities on ESP reading comprehension. Forty students from Razi University majoring in engineering course were selected for this study. The participants were classified into two groups, one control and one experimental. The results showed that employing prereading activities had positive effect on better comprehension. In addition, applying prereading activities was an important tool for facilitating the learners reading comprehension capacity.

\subsection{Anticipation guide and Comprehension}

Head and Readence (1992) believed that one way for promoting students motivation in reading is through activating prior knowledge. Activating what students know helps them to make prediction about what comes next in a text. All in all, it can promote individuals comprehension. In this regard, the researchers mentioned that lots of strategies like Possible Sentences, Direct Reading Thinking Activity, Guided writing Procedure, and anticipation guide have been developed to 
activate learners' prior knowledge. The researchers also found that through employing anticipation guide before starting to read first, students can activate their prior knowledge. Next, the students can promote their interest in text processing during reading. Then, anticipation guide can increase students' participation in post reading stage. The instructor can introduce a chapter by applying anticipation guide, in this way, learners can concentrate on topics mainly.

Kozen et al. (2006) examined middle school learners' chance for using and adapting anticipation guides. In this study, the researcher found when learners transmit from lower levels of education to upper levels their instructors encounter some difficulties, the difficulties related to the students' learning and their performances in instructional classrooms. Thus, using skills effectively in different levels of education especially at the middle and high school levels is crucial to academic success. This study also showed that content- area specialists concentrate on content area instruction and based on this article the researcher found that "in middle school, instruction focus on acquisition and proficiency of subject matter rather than acquisition and proficiency in reading" (p.196).

Another finding is that even the best readers struggle in the area of literacy, so the researchers noted that anticipation guide is a prereading strategy in improving students' content knowledge and reading comprehension. The findings also suggested that anticipation guide is an adequate tactic in developing "decoding skills, enhancing word meaning and strengthening comprehension" (p.196). In addition to this, disable learners can use anticipation guide as a prereading strategy to integrate knowledge and learning in content- area settings. The researchers also believed that anticipation guide strategy is an active process through which individuals can make prediction and it is a beneficial strategy in content area settings. It can evoke individual interest and encourage them to have active participation in class arguments about the topic because it can be implemented in small groups and by using anticipation guide all students can engage in problem solving. The researcher also found that it would be a plan for school improvement, it would be a study guide for those who have difficulty in learning and it can increase students' ability to read.

According to Jacobs (2010), by using anticipation guide, students take part in class discussion about the subject matter and this strategy encourages them to discover their thoughts and opinions.

\section{Research methodology}

\subsection{Participants:}

The participants of this study were composed of a group of $40 \mathrm{EFL}$ learners who had taken a proficiency test (PET). In other words, the individuals were selected based on their obtained scores on Preliminary English Test (PET). That is, those who were in intermediate level were selected by the researcher and they were randomly assigned into two groups: group one as experimental group and another as control group. In order to prevent gender effect all participants were female. The participants were selected from Bahar Language School in Shiraz, aged between 17 to 45. They were all native speakers of Persian.

\subsection{Instruments}

In the present study, several types of instruments were used for the purpose of data collection. The instruments are described below.

\subsubsection{Preliminary English Test (PET)}

In the present study, the researcher used an international standard test as a pretest in order to evaluate individuals' level of proficiency and ascertain that all individuals who participated in this study were in intermediate level.

The pretest was selected from Insight into PET. Insight into PET is for students who are going to take the Cambridge PET exam. The pretest has been chosen from practice test part. The practice test in Insight into PET contains several tests based on various skills, such as reading, writing, listening, and speaking but based on the purpose of this study, the researcher employed only the reading part as a pretest.

\subsubsection{Anticipation guide Worksheet}

Another trained expert in Bahar Language School in Shiraz used anticipation guide worksheet for teaching anticipation guide lesson. Reading sections in learners' instructional book were taught through anticipation guide lesson to group B. 
Anticipation guide worksheet is composed of some statements in the center of the page and two columns would be in both sides of each statement, one column was true and the other column was false. The individuals completed the left side before reading the passage and the right side of the statements were completed after reading the text. Below a sample of anticipation guide worksheet is shown.

Table 3.2. Anticipation Guide Worksheet

\begin{tabular}{|l|l|l|}
\hline Before reading & Statement & After reading \\
\hline & & \\
\hline & & \\
\hline & & \\
\hline & & \\
\hline & & \\
\hline
\end{tabular}

Source: Dr. Molly Ness' Presentation, November 3, 2006

\subsubsection{Reading Quizzes}

The researcher used 3 quizzes based on the three reading passages in Summit 1A. Each Quiz contained 6 questions. The questions were based on the passages concepts. All questions were free response items or open-ended items.

\subsubsection{Learners' Instructional Book: Summit 1A}

In this study, the researcher used Summit $1 \mathrm{~A}$ which was learners' instructional book as a research material. The focus of this study was on reading sections in that book. Summit 1A has been written by Joan Saslow and Allen Ascher (2006). This book contains 5 units and each unit has 1 reading section. Summit is a two-level high-intermediate to advanced communicative series for adults that can follow any intermediate course book.

\subsubsection{Reading Passages}

Three reading comprehension passages in their original form were selected by the researcher and were administered to the participants who were chosen based on their obtained scores on their proficiency test (PET. Passages all being of a culturally unfamiliar kind were taken from Summit 1A. The book was written by Joan Saslow and Allen Ascher (2006). Readability of the texts was estimated using the Flesch reading ease formula.

\subsubsection{Flesch-Kincaid Method}

In this study, the researcher used reading plus software in order to determine the grade level of the selected passages in learners' instructional book (Summit 1 A). Reading plus software contains Flesch reading formula. The Flesch/FleschKincaid readability tests are designed to indicate comprehension difficulty. It includes two parts: Flesch Reading Ease and Flesch-Kincaid Grade Level. In this formula, the score between 60 and 70 is acceptable. The following table shows ease of readability in a document.

Table 3.3. Ease of readability in a document

\begin{tabular}{|l|l|}
\hline $90-100:$ : very easy & $50-59:$ fairly difficult \\
\hline $80-89:$ easy & $30-49:$ difficult \\
\hline $70-79:$ fairly easy & $0-29:$ very confusing \\
\hline $60-69:$ standard
\end{tabular}

The two tests used the same core measures (word length and sentence length) but they have different weighting factors. So, the results of the two tests correlate approximately inversely: a text with a comparatively high score on the Reading Ease test should have a lower score on the Grade Level test. Both systems were devised by Rudolf Flesch. 


\subsection{Procedure}

The researcher used quasi experimental approach as the research method. Two groups were selected: one group as experimental group and another one as control. The participants were selected from Bahar Language School in Shiraz. In this study, the researcher accessed learners' level of proficiency to check that two groups of learners were homogenous. So, $40 \mathrm{EFL}$ learners took a proficiency test and individuals who were in level 9 which was an intermediate level were selected by the researcher.

The pretest was selected from Insight into PET. It was selected from practice test part. The practice test in Insight into PET contains several tests based on various skills such as reading, writing, listening, and speaking but based on the purpose of this study the researcher used only the reading part as a pretest.

The test is composed of five parts. The first part is composed of five questions; each question was a brief text and three choices. The individuals read each text and selected the best answer among different options. The second part is composed of five questions again. The questions in this part are about some people who want to choose the TV program and on the opposite page there was a description of eight programs. The individuals read each question and marked the correct letter. In part three, the individuals read a text about holidays in Patagonia and then they read some sentences based on the text and finally they circled A if the sentence was correct and if the sentence was incorrect, they chose B. In the fourth part, the individuals read a text and then they answered the questions based on the text, in other words, they selected the correct choice among different options. Part five was a cloze test. In this part, the individuals read a text and selected the correct word for each space. The individuals answered 35 questions in 45 minutes.

As mentioned above, for doing this investigation, the researcher needed two groups of participants and the researcher trained the groups' instructor.

Control group's instructor taught in her own way. So, the teacher thought each reading section without using strategy, in other words, passages were taught in traditional way to group A. Therefore, the control group's instructor applied the following procedures in her teaching schedules: first, she wrote the topic on the board. Second, she began a brief discussion about the topic. Third, she asked learners to answer some questions about the topic orally. Fourth, she asked learners to read the text independently. Fifth, she asked learners to listen carefully to the tape in order to understand the text and word pronunciation. Sixth, she wrote difficult words on the board and gave synonym for each word. Finally, she asked learners to answer reading comprehension questions and do some tasks such as summarizing texts or generating some questions.

The experimental group's instructor used anticipation guide process for teaching reading sections in learners' instructional book. Anticipation guide worksheet is composed of some statements and two columns in both sides of each statement. One column heading was before reading and the other one was after reading. The statements were prepared by the researcher. The researcher specified the purpose of the text and the statements were based on the text's objectives. Statements were typed from least argumentative to the most argumentative. Before teaching the reading sections in learners' instructional book to group B, the teacher gave an anticipation guide worksheet to each learner. The experimental group's instructor used the following steps for teaching anticipation guide lesson to group B. First, the instructor began teaching through warm up by considering the topic. Second, the individuals read each statement independently in order to be ready for class discussion, for doing this purpose before reading the text the individuals read each statement and specified whether the statement was true or false. Third, the individuals discussed each statement through group discussion. After the discussion, the individuals read the reading section in their instructional book individually, so, 5 to 10 minutes of class time was specified for independent reading, following the reading the participants recited each statement and discussed all in group again. In other words, they revisited each statement and they recorded whether the statement was true or false. After that the teacher collected anticipation guide worksheets and the individuals took an exam based on the passage.

\section{Results}

\subsection{Results Regarding Learners' Performances in Reading Comprehension Quizzes}

The first research question aimed to investigate if there is any significant improvement in Iranian EFL learners' performances on reading comprehension quizzes while using anticipation guide. The firsdt hypothesis was made in reply to this question. 
$\mathrm{H}_{01}$ : There is no significant improvement in Iranian EFL learners' performances on reading comprehension quizzes while using anticipation guide.

In order to investigate the improvement of the students' performances who used anticipation guide in the three quizzes, a One-Way Repeated Measures ANOVA was conducted on the dependent variable i.e., the scores of the quizzes. The descriptive data for the quiz scores of anticipation guide group are presented in Table 4.1. Moreover, the results of the One-Way Repeated Measures ANOVA are displayed in Table 4.2.

Table 4.1. Descriptive Statistics for the 3 Quizzes in Anticipation Guide Group

\begin{tabular}{|l|l|l|l|}
\hline & Mean & Std. Deviation & $\mathrm{N}$ \\
\hline Quiz 1 & 2.3250 & .81556 & 20 \\
\hline Quiz 2 & 3.1000 & .85224 & 20 \\
\hline Quiz 3 & 3.5000 & 1.06992 & 20 \\
\hline
\end{tabular}

Table 4.2. Multivariate Tests for the 3 quizzes in Anticipation Guide group

\begin{tabular}{|l|l|c|c|c|c|c|c|}
\hline \multicolumn{2}{|l|}{ Effect } & Value & $\mathrm{F}$ & Hypothesis df & Error df & Sig. & $\begin{array}{c}\text { Partial Eta } \\
\text { Squared }\end{array}$ \\
\hline \multirow{3}{*}{ Quizzes } & Pillai's Trace & .534 & $10.302^{\mathrm{a}}$ & 2.000 & 18.000 & .001 & .534 \\
\cline { 2 - 8 } & Wilks' Lambda & .466 & $10.302^{\mathrm{a}}$ & 2.000 & 18.000 & .001 & .534 \\
\cline { 2 - 8 } & $\begin{array}{l}\text { Hotelling's } \\
\text { Trace }\end{array}$ & 1.145 & $10.302^{\mathrm{a}}$ & 2.000 & 18.000 & .001 & .534 \\
\cline { 2 - 8 } & $\begin{array}{l}\text { Roy's Largest } \\
\text { Root }\end{array}$ & 1.145 & $10.302^{\mathrm{a}}$ & 2.000 & 18.000 & .001 & .534 \\
\hline $\begin{array}{l}\text { a. Exact statistic } \\
\text { Within Subjects Design: Quizzes }\end{array}$
\end{tabular}

As Table 4.1 shows, the subjects' mean score of the third quiz $(\mathrm{M}=3.5)$ is higher than the other two quizzes. Also, the mean score of the second quiz $(M=3.1)$ is slightly greater than that of the first quiz $(m=2.32)$. This indicates that the students who received the anticipation guide outperformed progressively from the first to the third quiz (see Figure 4.2). The results of one-way ANOVA, shown in Table 4.4, reveal that the difference in the quiz scores is statistically significant for the anticipation guide group, Wilks' Lambda $=.46, F(2,18)=10.30, p<.0005$, multivariate partial eta squared $=.53$. Table 4.2 suggests that there is a difference somewhere among the three groups but it does not tell us which set of scores (i.e., Quiz 1, Quiz 2, Quiz 3) differ from one another. This information is provided in Table 4.3, which compares each pair of quizzes and indicates whether the difference between them is significant.

Table 4.3. Pairwise Comparisons for the 3 quizzes in Anticipation Guide group

\begin{tabular}{|c|c|c|c|c|c|c|}
\hline \multirow{2}{*}{\multicolumn{2}{|c|}{ (I) Quizzes (J) Quizzes }} & \multirow{2}{*}{ Mean Difference $(\mathrm{I}-\mathrm{J})$} & \multirow{2}{*}{ Std. Error } & \multirow{2}{*}{ Sig. ${ }^{\text {a }}$} & \multicolumn{2}{|c|}{$95 \%$ Confidence Interval for Differencea } \\
\hline & & & & & Lower Bound & Upper Bound \\
\hline \multirow{2}{*}{1} & 2 & $-.775^{*}$ & .245 & .015 & -1.419 & -.131 \\
\hline & 3 & $-1.175^{*}$ & .253 & .001 & -1.838 & -.512 \\
\hline \multirow{2}{*}{2} & 1 & $.775^{*}$ & .245 & .015 & .131 & 1.419 \\
\hline & 3 & -.400 & .183 & .124 & -.879 & .079 \\
\hline \multirow{2}{*}{3} & 1 & $1.175^{*}$ & .253 & .001 & .512 & 1.838 \\
\hline & 2 & .400 & .183 & .124 & -.079 & .879 \\
\hline
\end{tabular}

Pairwise comparison in Table 4.3 shows that there is a statistically significant difference $(p<.05)$ between quiz 1 and the other two for the anticipation guide group; however, the difference between quiz 2 and 3 is not significant $(p>.05)$.

Therefore, these results demonstrate that the progression of the students' performance form quiz 1 to quiz 3 is statistically significant for the first to the second quiz but not for the second to third quiz.

Based on the observed results, it can be concluded that anticipation guide had a positive effect on the students' progression from the first to the other two quizzes. Consequently, Hypothesis 2 as there is no significant improvement in 
Iranian EFL learners' performances on reading comprehension quizzes while using anticipation guide is rejected except for quiz 2 to 3.

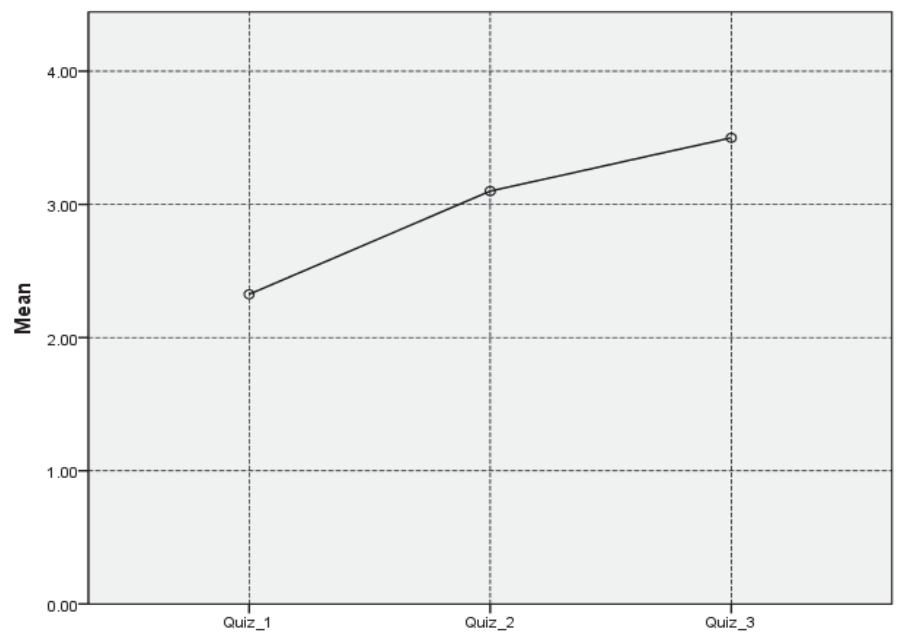

Figure 4.1. Quiz scores in Anticipation Guide group

\subsection{Results Regarding Pretest \& Posttest Given to Learners}

The second research question addressed the effect of using anticipation guide on Iranian EFL learners' reading comprehension. In response to this question, hypothesis two was formulated.

$\mathrm{H}_{02}$ : Anticipation guide does not have any effect on Iranian EFL learners' reading comprehension.

In order to examine the difference between the participants' scores on pretest and posttests, ANCOVA and pretests' covariate were used. Table 4.3 shows the descriptive data of the pretests and posttests in the experimental and control groups. The mean scores and standard deviations of pretests and posttests with respect to Anticipation guide and Control groups are presented in Table 4.3. As the tables show, the mean scores for the posttest is greater than the mean scores of pretest in the anticipation guide group; while, the mean scores of pretests and posttests are the same $(\mathrm{m}=$ 17.66) for the control group (see Figure 4.2). These results demonstrate that the decrease of scores from pretests to posttests, is statistically significant.

Table 4.3. Descriptive Statistics for Pretest and Posttest in Anticipation Guide

\begin{tabular}{|ll|c|c|c|c|c|}
\hline group & & N & Minimum & Maximum & Mean & Std. Deviation \\
\hline Anticipation & pre & 20 & 4.00 & 28.00 & 15.4500 & 4.93617 \\
& post1 & 20 & 9.00 & 28.00 & 19.1000 & 4.78924 \\
& Valid N (listwise) & 20 & & & & \\
\hline Control & pre & 18 & 13.00 & 24.00 & 17.6667 & 2.30089 \\
& post1 & 18 & 13.00 & 24.00 & 17.6667 & 2.30089 \\
& Valid N (listwise) & 18 & & & & \\
& & & & &
\end{tabular}




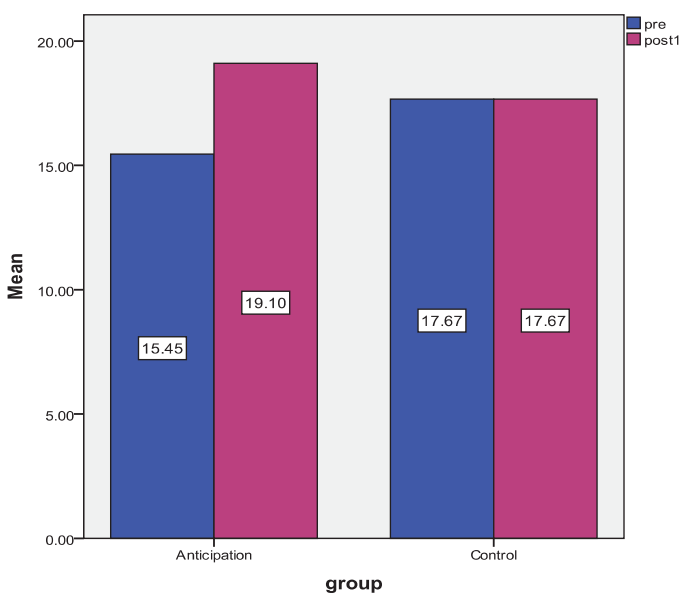

Figure 4.2. Pretest and Posttest Scores in Anticipation Guide and Control Groups

Table 4.5. shows that the groups' effect significant level is $(0.032)$ and it is more than $(0.5)$, it means that there is significant differences between posttests' scores in anticipation and control groups. So, the second null hypothesis $\left(\mathrm{H}_{02}\right)$ is rejected.

Table 4.4. ANCOVA for Groups' Effect on Posttest

\begin{tabular}{|c|c|c|c|c|c|}
\hline \multicolumn{6}{|c|}{ Tests of Between-Subjects Effects } \\
\hline \multicolumn{6}{|c|}{ Dependent Variable:post1 } \\
\hline Source & Type III Sum of Squares & df & Mean Square & $\mathrm{F}$ & Sig. \\
\hline Corrected Model & $153.360^{\mathrm{a}}$ & 2 & 76.680 & 6.848 & .003 \\
\hline Intercept & 200.597 & 1 & 200.597 & 17.915 & .000 \\
\hline group & 55.672 & 1 & 55.672 & 4.972 & .032 \\
\hline pre & 133.897 & 1 & 133.897 & 11.958 & .061 \\
\hline
\end{tabular}

Furthermore, $t$ test was run in order to examine the differences between pretest scores and the differences between the posttest scores in the experimental and in the control groups. The results from the t-tests are displayed in table 4.5. Table 4.6, also reveals that none of the pretest and posttest scores for any of the anticipation guide group and Control group has any significant differences because the $(\mathrm{Sig}=.082)$ and it is more than 0.5 .

Table 4.5. Independent Sample t Test for Pretest in anticipation guide and Control Groups

\begin{tabular}{|cc|c|c|c|c|}
\hline & group & $\mathrm{N}$ & Mean & Std. Deviation & Std. Error Mean \\
\hline pre & Anticipation & 20 & 15.4500 & 4.93617 & 1.10376 \\
& Control & 18 & 17.6667 & 2.30089 & .54233 \\
\hline
\end{tabular}

Table 4.6. Independent Sample $t$ Test for Pretest in anticipation guide and Control Groups

\begin{tabular}{|c|c|c|c|c|c|c|c|c|}
\hline & \multirow[b]{2}{*}{ Sig. } & \multirow[b]{2}{*}{$t$} & \multirow[b]{2}{*}{ df } & \multirow{2}{*}{$\begin{array}{c}\text { Sig. } \\
\text { (2-tailed) }\end{array}$} & \multirow{2}{*}{$\begin{array}{c}\text { Mean } \\
\text { Difference }\end{array}$} & \multirow{2}{*}{$\begin{array}{l}\text { Std. Error } \\
\text { Difference }\end{array}$} & \multicolumn{2}{|c|}{$\begin{array}{l}95 \% \text { Confidence Interval of } \\
\text { the Difference }\end{array}$} \\
\hline & & & & & & & Lower & Upper \\
\hline $\begin{array}{l}\text { Equal variances not } \\
\text { assumed }\end{array}$ & & -1.802 & 27.79 & 0.082 & -2.21667 & 1.22980 & -4.73790 & 0.30457 \\
\hline
\end{tabular}


The result of study showed that there was no significant improvement on EFL learners' performances on reading quizzes while using KWL charts and KWL charts did not have any positive effect on Iranian EFL learners' comprehension.

\section{Discussion}

Allen (2003), Keer and Verhaeghe (2005, as cited in Kirmizi, 2009) have suggested that applying reading comprehension strategies aid learners have effective reading process. Based on their findings, good readers can use some reading comprehension strategies such as making connection between the text context and their previous experience, sum up the text clues, evaluating anticipating questions based on the passage to be read in order to promote their reading comprehension. Cogmen and Saracaloglu (2009) examined students' usage of reading strategies in the faculty of education. The findings revealed that using reading strategies can promote learners academic success and proficient readers use reading tactics during reading process. Findings also showed that by using reading strategies, college students can promote their comprehension.

Anticipation guide as a prereading strategy arise learners' curiosity and provide authentic environment in class. Moreover, the mentioned prereading strategy helps students cooperate with each other during class discussion and this kind of cooperation can be useful for all aspects of their lives. Also, in this strategy, the students learn to plan before starting to read. So, it is one way to instruct students shoulder some responsibility and become more active throughout learning process.

Research Question 1: Is there any significant improvement in Iranian EFL learners' performances on reading comprehension quizzes while using anticipation guide?

Back to question \#1, and the null hypothesis above $\left(\mathrm{H}_{01}\right)$, the result showed that there was improvement in Iranian EFL learners' performances on reading comprehension quizzes while using anticipation guide but the improvement was not significant. In accord with Bell and Lee (2005), Anderson (1999), Ringler and Weber (1984), prereading strategies had influence on learners' activation of prior knowledge. Based on Pardo (2004), Harvey (2007), Block (1986), Wittrock (1983), Nagy (2006), prior knowledge also had an influence on learners' class participation. So, as the statistical results of the present study revealed activation of prior knowledge had a great impact on developing learners' group discussion through sharing their knowledge with their peers. In addition using prereading strategies helps learners activate their background knowledge. However, the improvement was not significant one reason may be was Immediate recall assessment in this study the learners take an exam immediately after reading each passage. As O' Brien suggested "immediate recall assessments cannot effectively measure whether the information was scaffolded enough to be successfully transferred into a student's long-term memory." (p.62). So, because of the small significant progress the second null hypothesis is rejected.

The findings of this study are in line with Yusuf (2011), Alemi and Ebadi (2010, Thongyon and Chiramanee (2011) that concentrated on prereading strategies. Yusuf (2011) conducted a study on this title "the effect of prereading activities on students' performance in reading comprehension in senior secondary schools". In this study 50 (male and female) students from two senior secondary schools were selected. The findings revealed that prereading activity had positive effect on learners' comprehension.

Also, Alemi and Ebadi (2010) investigated the effect of prereading activities on ESP reading comprehension. 40 students from Razi University majoring in engineering course were selected for this study. The participants were classified into two groups, one control and one experimental. The results showed that employing prereading activities had positive effect on better comprehension. In addition, applying prereading activities was an important tool for facilitating the learners reading comprehension capacity.

Thongyon and Chiramanee (2011) investigated on this title the effects of prereading activities on reading comprehension ability. 60 participants took part in this study. The researchers investigated both guessing story content by pictures and prereading questioning activities. The results showed that employing both prereading activities showed positive effect on students' comprehension but guessing story content by pictures was more effective than prereading questioning activities. Ringler and weber (1984, as cited in Yusuf, 2011) believed that prereading activities are enabling activities because they supply readers' sufficient background knowledge for better understanding.

According to Hansel (as cited in Taglieber et al., 1988, p. 456), "not only do prereading activities prepare native speakers for the concepts that follow, but by making the reading task easier and connecting the new content more meaningfully to prior knowledge, prereading activities make reading a more enjoyable task." 
Research Question 2: Does anticipation guide have any effects on Iranian EFL learners' reading comprehension?

Back to question \#2, the results of quantitative and statistical analysis of learners' pretest and posttest exam revealed that anticipation guide had significant impact on EFL learners' comprehension.

Şenay Şen (2009) surveyed the relationship between the use of metacognitive strategies and reading comprehension. The findings indicated that using special reading strategies help learners use their time proficiently. By using reading tactics, the period of reading can be easier and continues for learners. Using strategic reading skills aid learners develop their brain power. The results of the research studies on metacognition and reading comprehension showed that there is a relation between the two variables (metacognitive awareness \& reading comprehension). Proficient readers are those who use reading tactics in order to have critical reading. Findings also revealed that learners should inform about critical reading skills. In this way students should learn pre, during and after reading strategies. Learners should be conscious about prereading activities. These tactics aid learners prepare themselves for reading. By using during reading strategies learners can monitor their reading and post reading tactics help learners have an evaluation plan after reading. By using reading strategies students can understand what will happen at the end of the text and find the main idea. The results of this study showed that using metacognitive strategies such as find the main idea and guess the end of the text help students obtain high scores in the reading comprehension process in comparison to the students who instruct with traditional teaching.

Head and Readence (n.d.) believed that one way for promoting students motivation in reading is through activating prior knowledge. Activating what students know helps them to make prediction about what comes next in a text. All in all, it can promote individuals comprehension. In this regard, the researchers mentioned that lots of strategies like Possible Sentences, Direct Reading Thinking Activity, Guided writing Procedure, and anticipation guide have been developed to activate learners' prior knowledge.

Kozen et al. (2006) examined middle school learners' chance for using and adapting anticipation guide. The results of this study showed when learners transmit from lower levels of education to upper levels, their instructors encounter some difficulties, the difficulties related to the students' learning and their performances in instructional classrooms. Thus, using skills effectively in different levels of education especially at the middle and high school levels is crucial to academic success. This study also showed that content area specialists concentrate on content area instruction and based on this article, the researcher found that "in middle school, instruction focus on acquisition and proficiency of subject matter rather than acquisition and proficiency in reading" (p.196).

According to Jacobs (2010), by using anticipation guide, students take part in class discussion about the subject matter and this strategy encourages them to discover their thoughts and opinions. As a result, anticipation guide also helps students to be critical thinkers and able in understanding different kinds of information. This strategy prevents students to be just passive receivers of knowledge. This study also helps instructors to develop their capacity in finding different ways for removing instructional berries.

\section{References}

Alemi, M., \& Ebadi, S. (2011). The effects of pre-reading activities on ESP reading comprehension. Journal of Language Teaching and Research, 1 (5), 569-577.

Anderson, N.J. (1999). Exploring second language learning. Boston, MA: Heinle \& Heinle.

Armbruster, B. B., Lehr, F., \& Osborn, J. (2003). Put reading first: the research building block for teaching children to read,US: National Institute for Literacy.

Bainbridge, J., Pantaleo, S. (1999). Learning with literature in the Canadian Elementary Classroom. Unpublished doctoral dissertation. Alberta University Press, Duval House.

Baumann, J.T. et al (2007). Vocabulary Tricks: Effects of Instruction in Morphology and Context on Fifth-Grade Students' Ability to Derive and Infer Word Meanings. American Educational Research Journal, 40, 447-494.

Bell, L., Lee, C. (2005).using reading in content area strategies to improve students understanding in family and consumer sciences. Journal of Family and Consumer Sciences Education, 23(2), 35-45.

Block, E. (1986). The comprehension strategies of second language readers, TESOL Quarterly, 20, 463-494.

Bryant, D.P., Ugel, N., \&Thompson, S. (1999).Instructional strategies for content area reading instruction. Intervention in School and Clinic, 34(5), 293-302.

Chen, C. (2008). The effect of background knowledge and previews on elementary native Mandarian-Speaking English language learners' reading comprehension. Unpublished doctoral dissertation, University of Florida.

Cogmen, S., Saracaloglu, A.S. (2009). Students' usage of reading strategies in the faculty of education. Procedia Social and Behavioral Science, 1, 248-251. 
Cuffaro, H.K. (1995). Experimenting with the world: John Dowey and Early childhood classroom. U.S.A.: Teacher College Press.

Dole, J. A., Brown, K. J., Trathen, W. (1996). The effects of strategy Instruction on the comprehension performance of At-Risk students. Journal of Reading Research Quarterly, 31 (1), 62-88.

Ehri, L.C. (2001). Systematic Phonics Instruction Helps Students Learn to Read: Evidence from the National Reading Panel's MetaAnalysis. American

Educational Research Association, 71(3), 393-447.

Erten, I., Razi, S. (2009). The effects of cultural familiarity on reading comprehension. Reading in a Foreign Language, 21(1), 60-77.

Flood, J., Lapp, D., \& Fisher, D. (2003). Reading comprehension instruction. editors of book in James, F., Diane, L., James.R., S., \& Julie. M., J. (Eds.) handbook of research on teaching the English language arts. (2nd ed., pp. 931-941).

Fox, R.F. (1996). Harvesting mind: How TV commercials control kids. U.S.A.: Greenwood Publication Group.

Gunning, T.G. (1996). Creating reading instruction for all children. Boston, MA: Allyn \& Bacon.

Harvey, S., Goudvis, A. (2007). Strategies that work: Teaching comprehension for understanding \& engagement. (2 nd ed., 75-96). USA: Stenhouse publisher.

Head, M.H., \& Readencde, J. E. (1992). Anticipation guide: using prediction to promote learning from text. In E. K. Dishner, T.W. Bean, J.E. Readence and D. W. Moore (Eds.), Reading in the content areas: Improving classroom instruction (3 rd ed., 227-233). Dubugue: Kendall/Hunt.

Jacobs, V.A. (2010). Pre-, Guided-, and Post- Learning Purposes \& Strategies'. Retrieved May 12, 2010 from the World Wide Web: http://www.isites.harvard.edu/fs/docs/icb.topic.

Jacobson, E. (2007). Reading comprehension research and teaching strategies. Research Digest: evidence-based Reading Instruction, 8. Retrieved March 2, 2010 from the World Wide Web: http://www.calpro-online.org/documents/Adult.

Kirmizi, F.S. (2009). The relationship between writing achievement and the use of reading comprehension strategies in the 4th and 5th grades of primary schools. Procedia social and behavioral sciences, 1, 230-234.

Kozen, A.A., Murray, R.K., \& Windell, I. (2006). Increasing II students' chance to achieve: using and adapting anticipation guides with Middle school learners. Journal of Intervention in School and Clinic, 41 (4), 195-200.

Kreishan, R.A. \& Saidat, A.M. (2011). The effect of the religious and culture schemata on Jordanian students' comprehension of English texts. International Journal of Academic Research, 3(4), 339-347.

Morton, R.J. (2011). Phonological awareness and reading ability in children. Unpublished master thesis. Southern Illinois: University of Corbondale.

Murcia, M. (2001). Teaching English as a second or foreign language, Massachusetts: Heinle \& Heinle publishers.

O'Brien, k. (2007). The effect of pre reading strategies on the comprehension of culturally unfamiliar texts for adolescent English language learners. Unpublished doctoral dissertation, University of Hamline.

Pardo, L.S. (2004) what every teacher needs to know about comprehension. Journal of International Reading Association, 58 (3), $272-$ 280.

Rivers, W.M. (1981). Teaching foreign language skills. 2 nd ed. The University of Chicago Press.

Sedita, J. (2005). Effective vocabulary instruction. Journal of Insight on Learning Disabilities, 42(1), 45-67.

Snow, C. (2002). Reading for understanding: Toward an R \& D Program in Reading Comprehension. Santa Monica, CA: The RAND Corporation.

Taglieber, L., Johnson, L., \&Yarbrough, D. (1988). Effects of pre reading activities on EFL reading by Brazilian college students. TESOL Quarterly, 22,455-472.

Thongyon, N., \& Chiramance, T. (2011). The effects of pre-reading activities on reading comprehension ability. The 3rd International Conference of Humanities and Social Science.

Wittrock, M.C. (1983). Writing and the teaching of reading. Journal of Language Arts, 60 (5), 600-606.

Warsnak, A.D. (2006). The effects of activating prior knowledge before reading on students with and without learning disabilities. Unpublished doctoral thesis, University of Wichita State.

Yusuf, H. (2011). The effect of pre-reading activities on students' performance in reading comprehension in senior secondary schools. International research journal, 2(9), 1451-1455.

Zoghi, M., Mustapha, R., Rizan, Tg., Maasum, Tg. (2010). Looking into EFL reading comprehension. Elsevier Science Publisher, 7, 439445. 